Expert Rev Cardiovasc Ther. 2010 November ; 8(11): 1549-1558. doi:10.1586/erc.10.137.

\title{
Pulmonary hypertension in women
}

\author{
Meredith E Pugh ${ }^{1}$ and Anna R Hemnes ${ }^{\dagger, 1}$ \\ ${ }^{1}$ Division of Allergy, Pulmonary and Critical Care Medicine, Vanderbilt University Medical Center, \\ T1218 MCN, 1161 21st Avenue South, Nashville, TN 37232, USA
}

\begin{abstract}
Female predominance in pulmonary arterial hypertension (PAH) has been known for several decades and recent interest in the effects of sex hormones on the development of disease has substantially increased our understanding of this epidemiologic observation. Basic science data suggest a beneficial effect of estrogens in the pulmonary vasculature both acutely and chronically, which seems to contradict the known predilection in women. Recent human and rodent data have suggested that altered levels of estrogen, differential signaling and altered metabolism of estrogens in PAH may underlie the gender difference in this disease. Studies of the effects of sex hormones on the right ventricle in animal and human disease will further aid in understanding gender differences in PAH. This article focuses on the effects of sex hormones on the pulmonary vasculature and right ventricle on both a basic science and translational level.
\end{abstract}

\section{Keywords}

estrogen; gender; pulmonary arterial hypertension; pulmonary hypertension; pulmonary vasculature; sex hormones

Pulmonary hypertension is a heterogeneous group of disorders that all share the common feature of mean pulmonary artery pressure of $25 \mathrm{mmHg}$ or higher [1]. These diverse diseases include disorders that elevate left atrial pressure, such as left heart failure and valvular disease, advanced lung disease, chronic thromboembolic disease and disorders that affect the small pulmonary arteries in isolation; so-called pulmonary arterial hypertension (PAH) [1]. In PAH, progressive pulmonary arteriolar obstruction and obliteration ultimately result in right heart failure and death [2]. PAH can be idiopathic or heritable but is also associated with connective tissue disease, congenital left-to-right shunt, hemoglobinopathies, HIV disease, schistosomiasis and liver disease [1]. A strong female predominance of several types of PAH has been well demonstrated for over 30 years, yet the mechanisms that drive this predilection have largely been unknown. Recent basic science and clinical data are shedding new light on why this disease is at least three-times more frequent in women than men, and hopefully will result in improved therapeutic options in the near future. This article will discuss this emerging research along with recommendations for the care of female patients with PAH.

\footnotetext{
(C) 2010 Expert Reviews Ltd

${ }^{\dagger}$ Author for correspondence: Tel.: +1 615322 3412, Fax: +1 615343 3480, anna.r.hemnes@ vanderbilt.edu.

Financial \& competing interests disclosure

The authors have no other relevant affiliations or financial involvement with any organization or entity with a financial interest in or financial conflict with the subject matter or materials discussed in the manuscript apart from those disclosed.

No writing assistance was utilized in the production of this manuscript.
} 


\section{PAH overview}

\section{Classification of pulmonary hypertension}

Pulmonary hypertension is defined as a mean pulmonary artery pressure of $25 \mathrm{mmHg}$ or more. In 2008, the classification scheme for pulmonary hypertension was revised and the subtypes divided into five groups (Box 1). PAH, or group I, is the focus of this article, and encompasses diseases that primarily affect the small pulmonary vessels. Included within $\mathrm{PAH}$ are idiopathic and heritable forms of PAH, connective tissue disease-associated PAH, PAH caused by drug or toxins, schistosomiasis, portopulmonary hypertension, PAH associated with HIV, and other forms. These disease processes are manifested by progressive arteriolar obliteration and definitive diagnosis requires right heart catheterization with demonstration of a mean pulmonary artery pressure of $25 \mathrm{mmHg}$ or higher and a pulmonary artery occlusion pressure of $15 \mathrm{mmHg}$ or lower [1]. A subgroup denoted group 1 includes two rare disease processes that can be difficult to distinguish from idiopathic PAH antemortem: pulmonary veno-occlusive disease and pulmonary capillary hemangiomatosis. The other major causes of pulmonary hypertension (groups II-V) include pulmonary venous hypertension (secondary to left heart systolic or diastolic dysfunction or valvular disease; group II), pulmonary hypertension secondary to chronic lung disease and/or hypoxia (group III), chronic thromboembolic disease (group IV), and miscellaneous causes, such as sarcoidosis or mediastinal fibrosis (group V).

\section{Evaluation of pulmonary hypertension}

Evaluation of pulmonary hypertension involves determining the etiology for pulmonary hypertension, assessing the severity of disease and, finally, considering appropriate therapy. When pulmonary hypertension is suspected (usually by clinical symptoms of dyspnea and/or syncope or findings of right heart failure), echocardiography with Doppler estimation of pulmonary artery pressure often serves as a useful initial screening test. Echocardiography provides the additional advantage of evaluation of left-sided function and valves, helping to exclude pulmonary venous hypertension as a major contributing cause of pulmonary hypertension. A careful history and physical examination focusing on known risk factors, pulmonary function testing and chest imaging to detect structural anomalies and advanced lung disease, and ventilation perfusion lung scanning to evaluate for chronic thromboembolic disease, are other important aspects of the initial evaluation for pulmonary hypertension. Right heart catheterization is required for definitive diagnosis of $\mathrm{PAH}$, and also provides valuable information regarding disease severity and therapeutic options [2]. Vasodilator and fluid challenge performed during right heart catheterization help to identify patients responsive to calcium-channel blocker therapy and those with diastolic dysfunction, respectively.

\section{Box 1. Clinical classification of pulmonary hypertension}

- Group I: PAH

- Idiopathic PAH

- Heritable PAH

- Drug and toxin induced

- Associated with connective tissue disease, HIV, portopulmonary hypertension, schistosomiasis and chronic hemolytic anemia

- Group 1: Pulmonary veno-occlusive disease and/or pulmonary capillary hemangiomatosis 
- Group II: Pulmonary hypertension owing to left heart disease (including systolic and diastolic dysfunction, and valvular disease)

- Group III: Pulmonary hypertension owing to lung diseases and/or hypoxia

- Group IV: Chronic thromboembolic pulmonary hypertension

- Group V: Pulmonary hypertension with unclear multifactorial mechanisms (including hematologic disorders, sarcoidosis, pulmonary Langerhans cell histiocytosis and metabolic disorders)

PAH: Pulmonary arterial hypertension.

Modified from [1].

\section{Basic science of PAH}

A number of important pathways have been identified that lead to development of PAH. In seminal work evaluating families with heritable PAH, BMPR2 mutations were found to segregate faithfully with disease status. In these families, persons who were found to have $B M P R 2$ mutation had a one in five chance of developing PAH [3-5]. Further work has shown that heritable PAH was linked in a majority of cases to mutations in the same $B M P R 2$ gene, a TGF- $\beta$ superfamily member [3]. Mutations in this gene and altered expression have also been reported in other forms of PAH [6-9]. This membrane-bound receptor is nearly ubiquitous and it is as not yet known precisely how dysfunction causes PAH, though active research is ongoing and has recently pointed to differential cellular proliferation in BMPR2 dysfunction, altered cytoskeleton and cellular migration as well as defective angiogenesis [10-13]. Further research is needed to determine the critical affected pathways in PAH development. Additional pathways that play important roles in PAH development and have led to pharmacologic interventions include the prostacyclin pathway, which mediates vasoconstriction, platelet activation and vascular remodeling [14,15]; endothelin-1, a potent vasoconstrictor and mitogen [16,17]; and phosphodiesterase-5, which alters downstream signaling in the nitric oxide pathway $[15,18]$.

\section{Epidemiology}

Although older literature had suggested that PAH was exceptionally rare [2], modern registries have highlighted the relatively high prevalence of PAH in certain disease populations such as scleroderma and a slightly increasing prevalence in the aging general population. There are two major registries that have been published in the modern treatment era, the French Registry [19] and the Registry to Evaluate Early and Long-Term Pulmonary Arterial Hypertension Disease Management (REVEAL) [20], which collected cases from the USA. Both have shed light on PAH epidemiology today and raised important gender-related questions [19,20]. First, the French Registry showed a prevalence of 15 cases of PAH per 1 million persons in the population, which was substantially elevated from previous estimates $[19,20]$. While both studies confirmed the largest subcategory of PAH was idiopathic, there was a higher proportion of connective tissue disease-associated PAH in the REVEAL registry [19,21]. Mean age at the time of study was similar in the two registries.

The first papers describing what we now call idiopathic and heritable PAH demonstrated a clear female predominance in this disease, and these findings persist today [4,22]. Heritable PAH, most commonly caused by autosomal BMPR2 mutation, has a female-male ratio of nearly 2.7:1 and there is an unexplained increased number of females born to carriers of the mutation $[4,23,24]$. These findings of female predominance persist in PAH that is not genetically linked, that is, idiopathic PAH and connective tissue disease-associated PAH. Interestingly, there are discrepancies between France and the USA - the French Registry 
found a female-male ratio of 1.9:1 and the REVEAL registry found a ratio of 4.3:1 [19,20]. Differences in female predominance may be partially accounted for by the increased population of connective tissue disease-associated PAH in the REVEAL population, but are not completely explained by this difference in enrollment. Some have speculated that differences in environmental sex hormone exposures may underlie the observed ratios.

Other subcategories of PAH have been studied and show gender specificity. Portopulmonary hypertension affects females more than males $[25,26]$ and there is a strong female predominance in scleroderma-associated PAH $[27,28]$, with a nearly 10:1 female-male ratio in the REVEAL registry. This association is likely not adequately explained by the female predominance of scleroderma in general, with most reports suggesting a 2-5:1 ratio [29].

\section{Treatment}

While the morbidity and mortality of PAH remains substantial, the advent of three distinct classes of pulmonary vasodilators has improved survival in $\mathrm{PAH}$. The decision to initiate therapy and the selection of a vasodilator is often complex, and frequently reserved for subspecialty centers with an interdisciplinary team to assist and monitor response to therapy. Patients without right heart failure and a significant response to vasodilator testing during right heart catheterization (defined as a decrement in mean pulmonary artery pressure by at least $10 \mathrm{mmHg}$ to a mean pressure of $\leq 40 \mathrm{mmHg}$ ) can be initiated on calcium channel blocker therapy [30,31]. Unfortunately, this group of patients represents the minority of PAH. At present, there are eight US FDA-approved therapies for treatment of PAH. This includes the prostacyclins, which now include intravenous (epoprostenol and treprostinil), subcutaneous (treprostinil) and inhaled (iloprost and treprostinil) formulations, and remain a mainstay of PAH management. Two classes of oral agents are also available: the endothelin receptor antagonists (ambrisentan, bosentan and, in Europe, sitaxsentan) and phosphodiesterase-5 inhibitors (sildenafil and tadalafil). Combination therapy is frequently employed in progressive disease, but to date there remains little controlled data to suggest routine use of combinations of agents, with the exception of the PACES trial, which showed a mortality benefit with the addition of sildenafil to epoprostenol [32]. Randomized trials are currently underway to answer this important question.

Other symptomatic therapies for PAH are focused on management of heart failure with judicious use of diuretics and implementation of dietary salt and water restriction. Oxygen should be employed when appropriate to minimize hypoxia, which can worsen pulmonary hypertension. Anticoagulation with warfarin has been recommended on the basis of retrospective studies [33,34], but controlled trials are lacking. Lung transplantation is a consideration in selected individuals with progressive disease despite maximal medical therapy. Rarely, atrial septostomy is used as a salvage or palliative measure for end-stage PAH.

\section{PAH in women: understanding the epidemiology Potential hypotheses}

Female predominance in PAH prevalence can potentially be explained by several simple hypotheses. First, estrogen may be detrimental to the right ventricle (RV) or the pulmonary vasculature and thus influence development of pulmonary vascular disease or the right ventricular response to the stress of pulmonary hypertension. Second, testosterone may be beneficial for the pulmonary vasculature and RV, and lower levels in females inadequately protect from insults. Third, women have an environmental exposure that men do not, such as anorexigens, estrogenic medications or compounds, or other environmental exposure. Finally, other factors associated with being female increase risk, such as autoimmunity, pregnancy with exposure to fetal cells, or other indirect relationships. There is strong 
literature to support increased frequency of autoimmunity in females; however, this is not well studied as a causative factor in pulmonary vascular disease $[35,36]$. Similarly, there is limited literature on the environmental exposures in males and females that increase risk for pulmonary hypertension. While this would potentially be a fruitful avenue of future research, we have focused this article on the sex hormone effects in pulmonary hypertension owing to the limited literature on environmental exposures and pulmonary vascular disease. We will explore recent developments in animal models and human PAH regarding the effects of sex hormones and their metabolites on the development of pulmonary vascular disease.

\section{Sex hormone metabolism}

In order to understand the different potential actions of sex hormones and their metabolites on the pulmonary vasculature, a brief review of these compounds will be presented here. All steroid hormones are derived from cholesterol and are primarily synthesized in the gonads, adrenal glands and, in the case of pregnancy, the fetoplacental unit. Figure 1 depicts the conversion of cholesterol to sex hormones. First, cholesterol is converted to pregnenolone, which is then either metabolized through 17-hydroxy-pregnenolone to dehydroepiandrosterone (DHEA) and then to androstenedione or to progesterone. Progesterone is converted to testosterone and then, via the aromatase enzyme, to estradiol. Estradiol functions as the primary sex hormone in women, though it can be converted to the weaker estrogenic compound estrone or metabolized through other pathways. Using CYP1B1 and CYP1A1, estradiol is converted to the catechol estradiols, 2-hydroxyestradiol $\left(2-\mathrm{OHE}_{2}\right)$ or 4-hydroxyestradiol $\left(4-\mathrm{OHE}_{2}\right)$, which can in turn be converted via catechol-Omethyltransferase (COMT) to the methoxyestradiols, 2-methoxyestradiol (2-MEOE 2 ) or 4methoxyestradiol (4-MEOE 2 ). Estrone, conversely, is metabolized to $16 \alpha$-hydroxyestrogen $(16 \alpha-\mathrm{OHE})$. While estradiol is the primary sex hormone in women, there is growing literature that these other metabolites are not simply byproducts, but rather have independent and important actions of their own [23,37-40].

Estrogen acts through $\alpha$ - and $\beta$-receptors, which may be either cytosolic or membrane bound [41]. While classically thought to alter gene transcription, recent literature supports estrogen acting through an alternative, nonclassical G-protein-coupled receptor signaling pathway [42].

\section{Basic science: estrogen}

Both animal models of pulmonary hypertension and studies of isolated pulmonary vessels have been used to understand the effects of estrogens on the pulmonary vasculature. In isolated vessels exposed acutely to hypoxia or phenylephrine, both potent vasoconstrictors, estrogen has been shown to be vasodilatory in both male and female vessels, showing that estrogen's actions are present in both sexes [43]. Interestingly, physiologic estrogen fluctuation as seen with menstruation can attenuate pulmonary artery constrictor responses, thus suggesting that small changes in plasma estrogens can have major consequences for vascular function [43]. Estrogen mediates these effects through both $\alpha$ - and $\beta$-receptors using a nitric oxide-dependent mechanism [44].

Animal models to study pulmonary hypertension have been heavily criticized as not representing human disease adequately, but nonetheless gender differences have been shown in these models and they allow a platform to study the effects of estrogenic compounds that is not possible in humans. The two most commonly used rodent models are chronic exposure to hypoxia, which produces moderate, irreversible pulmonary hypertension, and monocrotaline, which is a vinca alkaloid that causes moderate pulmonary hypertension through extensive inflammatory lesions in the vasculature. Estrogen has been shown to 
attenuate disease in both models [37,45-47]. Ovariectomy in both hypoxia and monocrotaline models has been found to cause more severe pulmonary hypertension, supporting the protective role of estrogens in the pulmonary vasculature $[37,48]$. Interestingly, the non-estrogenic metabolite of estrogen, 2-MEOE 2 , attenuates both monocrotaline-induced pulmonary hypertension and also bleomycin-induced pulmonary hypertension and associated fibrosis in both male and female rats [37,38]. Thus, it appears that estrogen metabolites might be important mediators of the observed beneficial effects of estrogen in the pulmonary vasculature in the context of animal models and isolated vessel studies.

As we develop and gain experience with transgenic animal models of pulmonary hypertension, sex differences are beginning to be studied in these unique milieus. Interestingly, the two knockout mice strains with reported gender differences in development of pulmonary vascular disease, $\mathrm{VIP}^{-/-}$and $\mathrm{ApoE}^{-/-}$, both have a more severe phenotype in males $[49,50]$. New observations of the effects of estrogen on transgenic BMPR2 mutant mice should allow better understanding of how female sex affects the development of human heritable PAH [51,52]. Although these transgenic mice may not perfectly reflect human disease, as they are not haploinsufficient or dominant-negative mutations as are found in much heritable PAH, they still offer the opportunity to study this mutation in vivo.

As the RV is the primary mediator of survival in pulmonary hypertension, the effects of sex hormones in this organ may potentially mediate survival or predilection to disease in human PAH. Although there has been much exploration of the left ventricular effects of sex hormones, presently little is known about how estrogen and testosterone affect the RV's response to the load stress of pulmonary vascular disease. In the $\mathrm{VIP}^{-/-}$mouse described earlier female mice develop less RV hypertrophy than male mice, but this could be accounted for by less vascular disease in this transgenic model. More research on sex hormone effects in the RV are sorely needed as we begin to consider how manipulations in these pathways might affect the entire cardiopulmonary unit in animal models and human disease.

\section{Basic science: testosterone \& DHEA}

A potential explanation for the female predominance in human PAH is lower testosterone levels in females. There is ample laboratory evidence that testosterone acts as a pulmonary vasodilator acutely and that its effects are mediated not through classic androgen receptor signaling, but rather through a calcium antagonistic action [53-55]. However, male predominance in $\mathrm{VIP}^{-/-}$and $\mathrm{ApoE}^{-/-}$mice with pulmonary hypertension makes it unlikely that testosterone deprivation is the reason that human PAH occurs more often in women.

Dehydroepiandrosterone, which serves as a precursor to both testosterone and estrogens (Figure 1), has been considered a potentially important mediator of the female predominance in PAH. This hormone is synthesized in the adrenal glands and is produced at the highest level of all circulating steroid hormones. DHEA attenuates hypoxic vasoconstriction and protects against development of pulmonary hypertension in male rat models [56-58]. Further research is needed on this compound to discern its role in pulmonary hypertension.

In summary, estrogen appears to have beneficial effects on the pulmonary vasculature in terms of acute responses to vasoconstrictors and animal models of disease such as chronic hypoxia and monocrotaline. Increased male predominance in some transgenic models has thus far not been explained and the effects of sex hormones on the RV are unknown. Testosterone appears to be less important to the pulmonary vasculature based on very limited data. Thus, we have a discrepancy between the clear female predominance in human 
PAH and animal models showing a favorable effect of estrogen. This may be explained by differences in estrogen metabolism or differences in other sex hormones, such as testosterone and DHEA, or by differences between animal models and human disease.

\section{Clinical data}

There are emerging data in human disease that begin to explain female predominance in a handful of PAH subtypes.

Heritable \& idiopathic PAH_Although the nearly 3:1 male-female ratio in heritable PAH has been known for nearly three decades, the mechanism was largely unknown until now. BMPR2 mutation, which is autosomal dominant, would not be expected to have this ratio, unless there is a sex-specific modification that occurs in this disease or if there are fewer male children born to female carriers. Indeed, there are a slightly higher number of female children born to mutation carriers, but this is not enough to account for the observed differences. Gene arrays in both affected and unaffected $B M P R 2$ mutation carriers have implicated CYP1B1 as a potential reason why females are more affected in heritable PAH, as gene expression was approximately ten-times lower in affected female patients than unaffected female mutation carriers [23,59]. CYP1B1 is a cytochrome P450 enzyme that catalyzes oxidation of estrogens to $2-\mathrm{OHE}_{2}$ and $4-\mathrm{OHE}_{2}$ with known roles in tumorigenesis and metabolism of environmental toxins (Figure 1) [60-67]. If CYP1B1 expression were lower in only affected $B M P R 2$ mutation carriers, then the expected result would be an alteration in the levels of $2-\mathrm{OHE}_{2}$ and $16 \alpha-\mathrm{OHE}$ such that the potentially beneficial $2-\mathrm{OHE}_{2}$ level would be depressed and 16 $\alpha$-OHE would be accumulate as an alternative metabolic pathway. Austin and colleagues measured CYPIB1 genotypes in 140 mutation carriers and showed that wild-type $C Y P 1 B 1$ was more common in affected versus unaffected mutation carriers. They further explored the functional consequences of this genotype difference in urinary sex hormone excertion and showed that in affected mutation carriers the urinary ratio of $2-\mathrm{OHE}_{2}$ to $16 \alpha-\mathrm{OHE}$ was substantially lower compared with unaffected carriers [23]. These findings showed that altered estrogen metabolism through polymorphisms in CYP1B1 may account for the female predominance in heritable PAH and modify the risk of disease development in mutation carriers.

Recently, similar gene arrays have compared patients with idiopathic PAH to healthy controls and to patients with pulmonary hypertension due to advanced idiopathic pulmonary fibrosis. While showing clear alterations in the usual associations with PAH such as altered BMPR2 expression, these investigators also showed that women with PAH had higher expression levels of estrogen receptor $\alpha$ than normal women [68]. This again confirms the importance of estrogen signaling in $\mathrm{PAH}$, but the functional consequence of this data is not presently known.

Portopulmonary hypertension-There is an elevated risk of development of PAH in patients with cirrhosis, so called portopulmonary hypertension. In cirrhosis, Kawut and colleagues have shown through a large collaboration studying the pulmonary vascular consequences of cirrhosis that female sex and autoimmune hepatitis are risk factors for development of portopulmonary hypertension [25]. Roberts and colleagues have studied the same cohort to determine if common single-nucleotide polymorphisms segregate with development of disease. They showed that aromatase polymorphisms were more common in patients with portopulmonary hypertension and, importantly, these polymorphisms translate into higher estrogen levels in patients with portopulmonary hypertension than those with uncomplicated cirrhosis [26]. Estrogen metabolite levels in portopulmonary hypertension patients are not known, but this research combined with the heritable PAH data may suggest 
that higher levels of estrogen and its metabolites might potentiate portopulmonary hypertension in cirrhotic patients and, potentially, other susceptible groups.

Exogenous sex hormones in PAH-A frequently encountered clinical question is whether oral contraceptive or hormone replacement therapy use contribute to development of PAH and whether such drugs are contraindicated in established PAH. Unfortunately, there is presently very limited data on this topic. The burden of exposure to these compounds is heavy and the potential for these drugs to exacerbate underlying genetic tendencies to develop PAH is high [69]. In a small retrospective cohort of patients with scleroderma, hormone replacement therapy use was associated with a lower risk of development of PAH [70], while there is a report of rapid development of PAH in a patient with BMPR2 mutation after exposure to oral contraceptives [71]. These conflicting data in small numbers of patients do not allow meaningful conclusions to be drawn on the role of pharmaceutical or environmental estrogens in the development of PAH. A large-scale epidemiologic study of this topic would greatly improve our ability to make recommendations on their use or avoidance in patients at risk for PAH or with established disease.

Right ventricle \& sex hormones-Interest in RV effects of sex hormones has grown as there is greater recognition of the importance of this structure on morbidity and mortality in PAH. Human effects of estrogen and testosterone in right ventricular function have not been reported, but testosterone in particular is an intriguing potential mediator of right ventricular structure given its known pro-hypertrophic effects in skeletal muscle. The Multi-Ethnic Study of Atherosclerosis (MESA)-RV study will provide knowledge about the RV in healthy individuals and recent data have shown that higher DHEA levels are associated with worse RV function in both men and women without known pulmonary vascular disease [72]. Further data on this topic will hopefully help to explain differential survival in males and females with established PAH.

Prognosis-Although there is a strong preference for females developing PAH more frequently than males, the data on survival after disease diagnosis actually favor women [73,74]. In adult patients, male gender has been associated with higher mortality in both the REVEAL and French registries of PAH. In addition, in examining the pediatric cohort of patients with heritable $\mathrm{PAH}$, male gender is again associated with worse prognosis, although this difference does not persist in adulthood, where the male and female mortality is similar [23]. These observations about male mortality in pediatric heritable PAH are quite recent and underlying mechanisms are not presently known. In adult PAH patients undergoing equilibrium radionuclide angiography to measure right ventricular function, male sex was associated with lower right ventricular ejection fraction and even in normal males, right ventricular ejection fraction is lower in males [75,76]. It is possible that estrogen is important for development of pulmonary vascular disease, but survival, which is closely linked to right ventricular function, may be subject to different sex hormone effects; perhaps estrogens are beneficial in the RV's stress responses or testosterone is deleterious. Or, it is possible that with advanced pulmonary hypertension and diminished cardiac output in males, testosterone levels drop and this has a negative effect on right ventricular function. Alternatively, since male sex was most important in determining mortality when the patients were older than 60 years of age in the REVEAL registry, the effects of declining testosterone levels with age might be important in this older cohort [74]. It is likely that the sex hormone effects on development of pulmonary vascular disease and the effects on survival in established disease are different. 


\section{Recommendations for treating PAH in women}

\section{PAH treatment}

With the marked increase in treatment options and reported clinical trials of PAH therapy, we have had the opportunity to explore if there are any gender-specific differences in response to therapy. None of the large-scale trials showed that one sex benefitted more than the other from a particular therapy [77-85]. So selection of treatment for PAH in women is the same as for men and should follow well-established guidelines [30,86,87].

\section{Pregnancy}

While pregnancy is not proven to cause or accelerate development of PAH, it is often a time when disease presents owing to the increased cardiac output required to supply the fetoplacental unit and the fixed pulmonary vascular resistance in patients with PAH that cannot accommodate this increased flow. Not surprisingly, maternal mortality in pregnant PAH patients is high, ranging from 30 to $56 \%$ prior to availability of current PAH therapy [88]. A recent literature review of the effects of modern PAH treatment on maternal mortality showed that there have been some improvements, with mortality now ranging from $17 \%$ in idiopathic PAH and $28 \%$ in congenital heart disease-associated PAH up to $33 \%$ in other causes of PAH [89]. The primary risk factors for death that the authors identified were primagravid status and use of general anesthesia with delivery [89]. The risk of pregnancy is unacceptably high in PAH and we routinely counsel our patients on avoidance of pregnancy, preferably by sterilization. We have previously shown that hysteroscopic sterilization in this population is safe and well tolerated, thus avoiding risks of general anesthesia [90]. As endothelin receptor antagonists are pregnancy category X (i.e., known teratogens), these agents must only be used in women who are sterile, postmenopausal, are using two forms of birth control or have an intrauterine device (IUD) placed. Thus, it is our practice not to use these agents in women who remain of childbearing potential and are unwilling or unable to use birth control as recommended. In patients who present with a new diagnosis of PAH while pregnant, referral to a specialized center with extensive experience in PAH treatment and high-risk obstetricians will facilitate optimal management.

\section{Pharmaceutical estrogens}

The very limited and conflicting data on the risk of pharmaceutical estrogens in PAH development and the lack of data on the role of these compounds in progression of established disease do not presently allow literature-based recommendations to patients. It is our practice to discourage routine use of oral contraceptives or hormone replacement therapy in patients with PAH unless there is a compelling reason to do so. As mentioned previously, pregnancy avoidance often requires use of two forms of birth control or an IUD. We prefer IUDs when possible as they avoid significant systemic exposure to hormones.

\section{Expert commentatry \& five-year view}

There is strong interest in defining the molecular mechanisms that put patients at risk for development of or progression in PAH, and gender is the strongest modifier of risk in the general population. Modern registries such as the REVEAL registry and the French Registry have brought the female predominance of this disease to the forefront again. Understanding the gender difference in PAH is now being pursued on a molecular and epidemiologic level and it is likely that in the next 5 years we will better understand why PAH develops more often in females and whether environmental estrogen exposure contributes to disease development. Use of transgenic mouse models in particular will allow study of the basic mechanisms of the effects of sex hormones on the pulmonary vasculature. In addition, a 
growing body of literature on the RV will allow us to explore gender effects on this modifier of survival in PAH and potentially help us to explain the paradoxical findings of increased PAH development in women while men with established PAH die more rapidly.

On another front, both animal and human data have suggested that global derangement in metabolism driven by hormone alterations is present in PAH [10,50,91-94]. While discussion of these important developments is outside the scope of this article, we believe that the role of sex hormones in PAH development will likely be closely tied to other metabolic disorders such as insulin resistance. Thus, a combination of risk factors will converge to cause pulmonary vascular injury, altered repair and ultimately the clinical phenotype of PAH. With greater understanding of the role of hormonal changes in PAH, we will hopefully be able to make sound recommendations on the use of hormone replacement therapy and oral contraceptives. More basic and clinical data are needed prior to considering therapeutic manipulation of sex hormones in $\mathrm{PAH}$ or at-risk patient populations.

\section{Key issues}

- There is a strong female predominance in many forms of pulmonary arterial hypertension $(\mathrm{PAH})$.

- Animal and human data suggest that altered estrogen levels and altered metabolism of estrogens may underlie predisposition to PAH in certain groups.

- Sex hormones have effects on both the pulmonary vasculature and the right ventricle, the primary determinant of survival in PAH.

- Epidemiologic studies of sex hormone exposure in patients at risk for PAH may help discern the pulmonary vascular and right ventricular effects of these drugs in susceptible populations.

\section{Acknowledgments}

Anna R Hemnes has received grant support from Actelion and the NIH (1 K08 HL093363). She has served on the advisory boards and speakers bureaus for Actelion and Gilead.

\section{References}

Papers of special note have been highlighted as:

- of interest

•• of considerable interest

1. Simonneau G, Robbins IM, Beghetti M, et al. Updated clinical classification of pulmonary hypertension. J. Am. Coll. Cardiol. 2009; 54(1 Suppl.):S43-S54. [PubMed: 19555858]

2. D'Alonzo GE, Barst RJ, Ayres SM, et al. Survival in patients with primary pulmonary hypertension. Results from a national prospective registry. Ann. Intern. Med. 1991; 115(5):343-349. [PubMed: 1863023]

3. Lane KB, Machado RD, Pauciulo MW, et al. Heterozygous germline mutations in BMPR2, encoding a TGF- $\beta$ receptor, cause familial primary pulmonary hypertension. The International PPH Consortium. Nat. Genet. 2000; 26(1):81-84. [PubMed: 10973254]

4. Loyd JE, Butler MG, Foroud TM, Conneally PM, Phillips JA 3rd, Newman JH. Genetic anticipation and abnormal gender ratio at birth in familial primary pulmonary hypertension. Am. J. Respir. Crit. Care Med. 1995; 152(1):93-97. [PubMed: 7599869] 
5. Nichols WC, Koller DL, Slovis B, et al. Localization of the gene for familial primary pulmonary hypertension to chromosome 2q31-32. Nat. Genet. 1997; 15(3):277-280. [PubMed: 9054941]

6. Hamid R, Cogan JD, Hedges LK, et al. Penetrance of pulmonary arterial hypertension is modulated by the expression of normal BMPR2 allele. Hum. Mutat. 2009; 30(4):649-654. [PubMed: 19206171]

7. Roberts KE, McElroy JJ, Wong WP, et al. BMPR2 mutations in pulmonary arterial hypertension with congenital heart disease. Eur. Respir. J. 2004; 24(3):371-374. [PubMed: 15358693]

8. Elliott CG, Glissmeyer EW, Havlena GT, et al. Relationship of BMPR2 mutations to vasoreactivity in pulmonary arterial hypertension. Circulation. 2006; 113(21):2509-2515. [PubMed: 16717148]

9. Thomson JR, Machado RD, Pauciulo MW, et al. Sporadic primary pulmonary hypertension is associated with germline mutations of the gene encoding BMPR-II, a receptor member of the TGF$\beta$ family. J. Med. Genet. 2000; 37(10):741-745. [PubMed: 11015450]

10. Hansmann G, de Jesus Perez VA, Alastalo TP, et al. An antiproliferative BMP-2/PPAR $\gamma /$ apoE axis in human and murine SMCs and its role in pulmonary hypertension. J. Clin. Invest. 2008; 118(5): 1846-1857. [PubMed: 18382765]

11. Gamell C, Osses N, Bartrons R, et al. BMP2 induction of actin cytoskeleton reorganization and cell migration requires PI3-kinase and Cdc42 activity. J. Cell Sci. 2008; 121(Pt 23):3960-3970. [PubMed: 19001503]

12. Wojciak-Stothard B, Tsang LY, Haworth SG. Rac and Rho play opposing roles in the regulation of hypoxia/reoxygenation-induced permeability changes in pulmonary artery endothelial cells. Am. J. Physiol. Lung Cell. Mol. Physiol. 2005; 288(4):L749-L760. [PubMed: 15591411]

13. Wojciak-Stothard B, Tsang LY, Paleolog E, Hall SM, Haworth SG. Rac1 and RhoA as regulators of endothelial phenotype and barrier function in hypoxia-induced neonatal pulmonary hypertension. Am. J. Physiol. Lung Cell. Mol. Physiol. 2006; 290(6):L1173-L1182. [PubMed: 16428270]

14. Christman BW, McPherson CD, Newman JH, et al. An imbalance between the excretion of thromboxane and prostacyclin metabolites in pulmonary hypertension. N. Engl. J. Med. 1992; 327(2):70-75. [PubMed: 1603138]

15. Humbert M, Sitbon O, Simonneau G. Treatment of pulmonary arterial hypertension. N. Engl. J. Med. 2004; 351(14):1425-1436. [PubMed: 15459304]

16. Giaid A, Saleh D, Yanagisawa M, Forbes RD. Endothelin-1 immunoreactivity and mRNA in the transplanted human heart. Transplantation. 1995; 59(9):1308-1313. [PubMed: 7762067]

17. Giaid A, Yanagisawa M, Langleben D, et al. Expression of endothelin-1 in the lungs of patients with pulmonary hypertension. N. Engl. J. Med. 1993; 328(24):1732-1739. [PubMed: 8497283]

18. Champion HC, Bivalacqua TJ, D'Souza FM, et al. Gene transfer of endothelial nitric oxide synthase to the lung of the mouse in vivo. Effect on agonist-induced and flow-mediated vascular responses. Circ. Res. 1999; 84(12):1422-1432. [PubMed: 10381895]

19. Humbert M, Sitbon O, Chaouat A, et al. Pulmonary arterial hypertension in France: results from a national registry. Am. J. Respir. Crit. Care Med. 2006; 173(9):1023-1030. [PubMed: 16456139]

20. Badesch DB, Raskob GE, Elliott CG, et al. Pulmonary arterial hypertension: baseline characteristics from the REVEAL Registry. Chest. 2010; 137(2):376-387. [PubMed: 19837821] • Describes enhanced female-to-male ratio in modern registry.

21. Badesch DB, Champion HC, Sanchez MA, et al. Diagnosis and assessment of pulmonary arterial hypertension. J. Am. Coll. Cardiol. 2009; 54(1 Suppl.):S55-S66. [PubMed: 19555859]

22. Rich S, Dantzker DR, Ayres SM, et al. Primary pulmonary hypertension. A national prospective study. Ann. Intern. Med. 1987; 107(2):216-223. [PubMed: 3605900]

23. Austin ED, Cogan JD, West JD, et al. Alterations in estrogen metabolism: implications for higher penetrance of FPAH in females. Eur. Respir. J. 2009; 34(5):1093-1099. [PubMed: 19357154] •• Shows altered estrogen metabolism in human pulmonary arterial hypertension (PAH).

24. Machado RD, Pauciulo MW, Thomson JR, et al. BMPR2 haploinsufficiency as the inherited molecular mechanism for primary pulmonary hypertension. Am. J. Hum. Genet. 2001; 68(1):92102. [PubMed: 11115378]

25. Kawut SM, Krowka MJ, Trotter JF, et al. Clinical risk factors for portopulmonary hypertension. Hepatology. 2008; 48(1):196-203. [PubMed: 18537192] 
26. Roberts KE, Fallon MB, Krowka MJ, et al. Genetic risk factors for portopulmonary hypertension in patients with advanced liver disease. Am. J. Respir. Crit. Care Med. 2009; 179(9):835-842. [PubMed: 19218192] • Highlights female predominance in portopulmonary PAH and links to altered aromatase activity.

27. Chung L, Liu J, Parsons L, et al. Characterization of connective tissue disease associated pulmonary arterial hypertension from the REVEAL registry: identifying systemic sclerosis as a unique phenotype. Chest. 2010 (Epub ahead of print).

28. Fisher MR, Mathai SC, Champion HC, et al. Clinical differences between idiopathic and scleroderma-related pulmonary hypertension. Arthritis Rheum. 2006; 54(9):3043-3050. [PubMed: 16947776]

29. Chifflot H, Fautrel B, Sordet C, Chatelus E, Sibilia J. Incidence and prevalence of systemic sclerosis: a systematic literature review. Semin. Arthritis Rheum. 2008; 37(4):223-235. [PubMed: 17692364]

30. McLaughlin VV, Archer SL, Badesch DB, et al. ACCF/AHA 2009 expert consensus document on pulmonary hypertension a report of the American College of Cardiology Foundation Task Force on Expert Consensus Documents and the American Heart Association developed in collaboration with the American College of Chest Physicians; American Thoracic Society, Inc.; and the Pulmonary Hypertension Association. J. Am. Coll. Cardiol. 2009; 53(17):1573-1619. [PubMed: 19389575]

31. Sitbon O, Humbert M, Jais X, et al. Long-term response to calcium channel blockers in idiopathic pulmonary arterial hypertension. Circulation. 2005; 111(23):3105-3111. [PubMed: 15939821]

32. Simonneau G, Rubin LJ, Galie N, et al. Addition of sildenafil to long-term intravenous epoprostenol therapy in patients with pulmonary arterial hypertension: a randomized trial. Ann. Intern. Med. 2008; 149(8):521-530. [PubMed: 18936500]

33. Frank H, Mlczoch J, Huber K, Schuster E, Gurtner HP, Kneussl M. The effect of anticoagulant therapy in primary and anorectic drug-induced pulmonary hypertension. Chest. 1997; 112(3):714721. [PubMed: 9315805]

34. Johnson SR, Mehta S, Granton JT. Anticoagulation in pulmonary arterial hypertension: a qualitative systematic review. Eur. Respir. J. 2006; 28(5):999-1004. [PubMed: 17074918]

35. Collins N, Bastian B, Quiqueree L, Jones C, Morgan R, Reeves G. Abnormal pulmonary vascular responses in patients registered with a systemic autoimmunity database: Pulmonary Hypertension Assessment and Screening Evaluation using stress echocardiography (PHASE-I). Eur. J. Echocardiogr. 2006; 7(6):439-446. [PubMed: 16431161]

36. Sweeney L, Voelkel NF. Estrogen exposure, obesity and thyroid disease in women with severe pulmonary hypertension. Eur. J. Med. Res. 2009; 14(10):433-442. [PubMed: 19748850]

37. Tofovic SP, Zhang X, Jackson EK, Dacic S, Petrusevska G. 2-methoxyestradiol mediates the protective effects of estradiol in monocrotaline-induced pulmonary hypertension. Vascul. Pharmacol. 2006; 45(6):358-367. [PubMed: 16872912] • Shows importance of altered estrogen metabolism in a mouse model of PAH.

38. Tofovic SP, Zhang X, Jackson EK, Zhu H, Petrusevska G. 2-methoxyestradiol attenuates bleomycin-induced pulmonary hypertension and fibrosis in estrogen-deficient rats. Vascul. Pharmacol. 2009; 51(2-3):190-197. [PubMed: 19540933]

39. Tofovic SP, Zhang X, Jackson EK, Zhu H, Petrusevska G. 2-methoxyestradiol attenuates bleomycin-induced pulmonary hypertension and fibrosis in estrogen-deficient rats. Vascul. Pharmacol. 2009; 51(2-3):190-197. [PubMed: 19540933]

40. Tofovic SP, Zhang X, Zhu H, Jackson EK, Rafikova O, Petrusevska G. 2-ethoxyestradiol is antimitogenic and attenuates monocrotaline-induced pulmonary hypertension and vascular remodeling. Vascul. Pharmacol. 2008; 48(4-6):174-183. [PubMed: 18373958]

41. Zhu BT, Conney AH. Functional role of estrogen metabolism in target cells: review and perspectives. Carcinogenesis. 1998; 19(1):1-27. [PubMed: 9472688]

42. Meldrum DR. G-protein-coupled receptor 30 mediates estrogen's nongenomic effects after hemorrhagic shock and trauma. Am. J. Pathol. 2007; 170(4):1148-1151. [PubMed: 17392155]

43. Lahm T, Patel KM, Crisostomo PR, et al. Endogenous estrogen attenuates pulmonary artery vasoreactivity and acute hypoxic pulmonary vasoconstriction: the effects of sex and menstrual 
cycle. Am. J. Physiol. Endocrinol. Metab. 2007; 293(3):E865-E871. [PubMed: 17595218] • Explores acute effects of estrogen on pulmonary vasculature.

44. Lahm T, Crisostomo PR, Markel TA, et al. Selective estrogen receptor- $\alpha$ and estrogen receptor- $\beta$ agonists rapidly decrease pulmonary artery vasoconstriction by a nitric oxide dependent mechanism. Am. J. Physiol. Regul. Integr. Comp. Physiol. 2008; 295(5):R1486-R1493. [PubMed: 18832085]

45. Moore LG, McMurtry IF, Reeves JT. Effects of sex hormones on cardiovascular and hematologic responses to chronic hypoxia in rats. Proc. Soc. Exp. Biol. Med. 1978; 158(4):658-662. [PubMed: 151282]

46. Rabinovitch M, Gamble WJ, Miettinen OS, Reid L. Age and sex influence on pulmonary hypertension of chronic hypoxia and on recovery. Am. J. Physiol. 1981; 240(1):H62-H72. [PubMed: 6450541]

47. McMurtry IF, Frith CH, Will DH. Cardiopulmonary responses of male and female swine to simulated high altitude. J. Appl. Physiol. 1973; 35(4):459-462. [PubMed: 4270292]

48. Resta TC, Kanagy NL, Walker BR. Estradiol-induced attenuation of pulmonary hypertension is not associated with altered eNOS expression. Am. J. Physiol. Lung Cell. Mol. Physiol. 2001; 280(1):L88-L97. [PubMed: 11133498]

49. Said SI, Hamidi SA, Dickman KG, et al. Moderate pulmonary arterial hypertension in male mice lacking the vasoactive intestinal peptide gene. Circulation. 2007; 115(10):1260-1268. [PubMed: 17309917]

50. Hansmann G, Wagner RA, Schellong S, et al. Pulmonary arterial hypertension is linked to insulin resistance and reversed by peroxisome proliferator-activated receptor- $\gamma$ activation. Circulation. 2007; 115(10):1275-1284. [PubMed: 17339547]

51. West J, Harral J, Lane K, et al. Mice expressing BMPR2r899x transgene in smooth muscle develop pulmonary vascular lesions. Am. J. Physiol. Lung Cell. Mol. Physiol. 2008; 295(5):L744-L755. [PubMed: 18723761]

52. West J, Fagan K, Steudel W, et al. Pulmonary hypertension in transgenic mice expressing a dominant-negative BMPRII gene in smooth muscle. Circ. Res. 2004; 94(8):1109-1114. [PubMed: 15031260]

53. English KM, Jones RD, Jones TH, Morice AH, Channer KS. Gender differences in the vasomotor effects of different steroid hormones in rat pulmonary and coronary arteries. Horm. Metab. Res. 2001; 33(11):645-652. [PubMed: 11733866]

54. Jones RD, English KM, Pugh PJ, Morice AH, Jones TH, Channer KS. Pulmonary vasodilatory action of testosterone: evidence of a calcium antagonistic action. J. Cardiovasc. Pharmacol. 2002; 39(6):814-823. [PubMed: 12021575]

55. Smith AM, Bennett RT, Jones TH, Cowen ME, Channer KS, Jones RD. Characterization of the vasodilatory action of testosterone in the human pulmonary circulation. Vasc. Health Risk Manag. 2008; 4(6):1459-1466. [PubMed: 19337559]

56. Farrukh IS, Peng W, Orlinska U, Hoidal JR. Effect of dehydroepiandrosterone on hypoxic pulmonary vasoconstriction: a Ca ${ }^{(2+)}$-activated $\mathrm{K}^{(+)}$-channel opener. Am. J. Physiol. 1998; 274(2 Pt 1):L186-L195. [PubMed: 9486202]

57. Homma N, Nagaoka T, Karoor V, et al. Involvement of RhoA/Rho kinase signaling in protection against monocrotaline-induced pulmonary hypertension in pneumonectomized rats by dehydroepiandrosterone. Am. J. Physiol. Lung Cell. Mol. Physiol. 2008; 295(1):L71-L78. [PubMed: 18469113]

58. Oka M, Karoor V, Homma N, et al. Dehydroepiandrosterone upregulates soluble guanylate cyclase and inhibits hypoxic pulmonary hypertension. Cardiovasc. Res. 2007; 74(3):377-387. [PubMed: 17346686]

59. West J, Cogan J, Geraci M, et al. Gene expression in BMPR2 mutation carriers with and without evidence of pulmonary arterial hypertension suggests pathways relevant to disease penetrance. BMC Med. Genomics. 2008; 1:45. [PubMed: 18823550]

60. Diergaarde B, Potter JD, Jupe ER, et al. Polymorphisms in genes involved in sex hormone metabolism, estrogen plus progestin hormone therapy use, and risk of postmenopausal breast cancer. Cancer Epidemiol. Biomarkers Prev. 2008; 17(7):1751-1759. [PubMed: 18628428] 
61. Kim JH, Sherman ME, Curriero FC, Guengerich FP, Strickland PT, Sutter TR. Expression of cytochromes P450 1A1 and 1B1 in human lung from smokers, non-smokers, and ex-smokers. Toxicol. Appl. Pharmacol. 2004; 199(3):210-219. [PubMed: 15364538]

62. Roos PH, Bolt HM. Cytochrome P450 interactions in human cancers: new aspects considering CYP1B1. Expert Opin. Drug Metab. Toxicol. 2005; 1(2):187-202. [PubMed: 16922636]

63. Sorensen M, Autrup H, Tjonneland A, Overvad K, Raaschou-Nielsen O. Genetic polymorphisms in CYP1B1, GSTA1, NQO1 and NAT2 and the risk of lung cancer. Cancer Lett. 2005; 221(2):185190. [PubMed: 15808404]

64. Spivack SD, Hurteau GJ, Reilly AA, Aldous KM, Ding X, Kaminsky LS. CYP1B1 expression in human lung. Drug Metab. Dispos. 2001; 29(6):916-922. [PubMed: 11353763]

65. Wenzlaff AS, Cote ML, Bock CH, et al. CYP1A1 and CYP1B1 polymorphisms and risk of lung cancer among never smokers: a population-based study. Carcinogenesis. 2005; 26(12):2207-2212. [PubMed: 16051642]

66. Yager JD, Davidson NE. Estrogen carcinogenesis in breast cancer. N. Engl. J. Med. 2006; 354(3): 270-282. [PubMed: 16421368]

67. Muti P, Bradlow HL, Micheli A, et al. Estrogen metabolism and risk of breast cancer: a prospective study of the 2:16 $\alpha$-hydroxyestrone ratio in premenopausal and postmenopausal women. Epidemiology. 2000; 11(6):635-640. [PubMed: 11055622]

68. Rajkumar R, Konishi K, Richards TJ, et al. Genomewide RNA expression profiling in lung identifies distinct signatures in idiopathic pulmonary arterial hypertension and secondary pulmonary hypertension. Am. J. Physiol. Heart Circ. Physiol. 2010; 298(4):H1235-H1248. [PubMed: 20081107]

69. Wagner JD, Kaplan JR, Burkman RT. Reproductive hormones and cardiovascular disease mechanism of action and clinical implications. Obstet. Gynecol. Clin. North Am. 2002; 29(3): 475-493. [PubMed: 12353669]

70. Beretta L, Caronni M, Origgi L, Ponti A, Santaniello A, Scorza R. Hormone replacement therapy may prevent the development of isolated pulmonary hypertension in patients with systemic sclerosis and limited cutaneous involvement. Scand. J. Rheumatol. 2006; 35(6):468-471. [PubMed: 17343256]

71. Morse JH, Horn EM, Barst RJ. Hormone replacement therapy: a possible risk factor in carriers of familial primary pulmonary hypertension. Chest. 1999; 116(3):847. [PubMed: 10492306]

72. Ventetuolo CE, Ouyang P, Bluemke DA, et al. Sex hormones and the right ventricle: the MESAright ventricle study. Am. J. Respir. Crit. Care Med. 2009; 179 (Abstract A4150).

73. Humbert M, Sitbon O, Yaici A, et al. Survival in incident and prevalent cohorts of patients with pulmonary arterial hypertension. Eur. Respir. J. 2010; 36(3):549-555. [PubMed: 20562126]

74. Benza RL, Miller DP, Gomberg-Maitland M, et al. Predicting survival in pulmonary arterial hypertension. Insights from the Registry to Evaluate Early and Long-Term Pulmonary Arterial Hypertension Disease Management (REVEAL). Circulation. 2010; 122(2):164-172. [PubMed: 20585012] - Shows worse outcomes in males with PAH.

75. Kawut SM, Al-Naamani N, Agerstrand C, et al. Determinants of right ventricular ejection fraction in pulmonary arterial hypertension. Chest. 2009; 135(3):752-759. [PubMed: 18849396]

76. Tandri H, Daya SK, Nasir K, et al. Normal reference values for the adult right ventricle by magnetic resonance imaging. Am. J. Cardiol. 2006; 98(12):1660-1664. [PubMed: 17145230]

77. Galie N, Brundage BH, Ghofrani HA, et al. Tadalafil therapy for pulmonary arterial hypertension. Circulation. 2009; 119(22):2894-2903. [PubMed: 19470885]

78. Galie N, Ghofrani HA, Torbicki A, et al. Sildenafil citrate therapy for pulmonary arterial hypertension. N. Engl. J. Med. 2005; 353(20):2148-2157. [PubMed: 16291984]

79. Rubin LJ, Badesch DB, Barst RJ, et al. Bosentan therapy for pulmonary arterial hypertension. N. Engl. J. Med. 2002; 346(12):896-903. [PubMed: 11907289]

80. Galie N, Badesch D, Oudiz R, et al. Ambrisentan therapy for pulmonary arterial hypertension. J. Am. Coll. Cardiol. 2005; 46(3):529-535. [PubMed: 16053970]

81. Higenbottam T. Intravenous epoprostenol for primary pulmonary hypertension. N. Engl. J. Med. 1996; 334(22):1477. author reply 1477-1478. [PubMed: 8618595]

Expert Rev Cardiovasc Ther. Author manuscript; available in PMC 2011 September 1. 
82. McLaughlin VV, Shillington A, Rich S. Survival in primary pulmonary hypertension: the impact of epoprostenol therapy. Circulation. 2002; 106(12):1477-1482. [PubMed: 12234951]

83. Barst RJ, Rubin LJ, Long WA, et al. A comparison of continuous intravenous epoprostenol (prostacyclin) with conventional therapy for primary pulmonary hypertension. The Primary Pulmonary Hypertension Study Group. N. Engl. J. Med. 1996; 334(5):296-302. [PubMed: 8532025]

84. Olschewski H, Simonneau G, Galie N, et al. Inhaled iloprost for severe pulmonary hypertension. N. Engl. J. Med. 2002; 347(5):322-329. [PubMed: 12151469]

85. Channick RN, Olschewski H, Seeger W, Staub T, Voswinckel R, Rubin LJ. Safety and efficacy of inhaled treprostinil as add-on therapy to bosentan in pulmonary arterial hypertension. J. Am. Coll. Cardiol. 2006; 48(7):1433-1437. [PubMed: 17010807]

86. Galie N, Hoeper MM, Humbert M, et al. Guidelines for the diagnosis and treatment of pulmonary hypertension. Eur. Respir. J. 2009; 34(6):1219-1263. [PubMed: 19749199]

87. Barst RJ, Gibbs JS, Ghofrani HA, et al. Updated evidence-based treatment algorithm in pulmonary arterial hypertension. J. Am. Coll. Cardiol. 2009; 54(1 Suppl.):S78-S84. [PubMed: 19555861]

88. Weiss BM, Zemp L, Seifert B, Hess OM. Outcome of pulmonary vascular disease in pregnancy: a systematic overview from 1978 through 1996. J. Am. Coll. Cardiol. 1998; 31(7):1650-1657. [PubMed: 9626847]

89. Bedard E, Dimopoulos K, Gatzoulis MA. Has there been any progress made on pregnancy outcomes among women with pulmonary arterial hypertension? Eur. Heart J. 2009; 30(3):256265. [PubMed: 19147605]

90. Hemnes AR, Robbins IM. Hysteroscopic sterilization in women with pulmonary vascular disease. Mayo Clin. Proc. 2008; 83(10):1188-1189. author reply 1189. [PubMed: 18828983]

91. Hansmann G, Rabinovitch M. The protective role of adiponectin in pulmonary vascular disease. Am. J. Physiol. Lung Cell. Mol. Physiol. 2010; 298(1):L1-L2. [PubMed: 19880503]

92. Rabinovitch M. PPAR $\gamma$ and the pathobiology of pulmonary arterial hypertension. Adv. Exp. Med. Biol. 2010; 661:447-458. [PubMed: 20204748]

93. Zamanian RT, Hansmann G, Snook S, et al. Insulin resistance in pulmonary arterial hypertension. Eur. Respir. J. 2009; 33(2):318-324. [PubMed: 19047320]

94. Robbins IM, Newman JH, Johnson RF, et al. Association of the metabolic syndrome with pulmonary venous hypertension. Chest. 2009; 136(1):31-36. [PubMed: 19188551] 


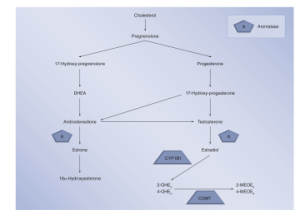

Figure 1. Sex hormone metabolism

2-MEOE 2 : 2-Methoxyestradiol; 2-OHE 2 : 2-Hydroxyestradiol; 4-MEOE 2 : 4-

Methoxyestradiol; 4-OHE 2 : 4-Hydroxyestradiol; COMT: Catechol- $O$-methyltransferase; DHEA: Dehydroepiandrosterone. 
Table 1

Summary of sex hormone data in rodents and humans.

\begin{tabular}{|lll|}
\hline Sex hormone & Animal data & Human data \\
\hline Estrogen & $\begin{array}{l}\text { Estrogen may be beneficial acutely; metabolites of estrogen are } \\
\text { the primary mediators of this benefit }\end{array}$ & $\begin{array}{l}\text { Altered estrogen levels and metabolism are implicated in } \\
\text { heritable PAH and portopulmonary PAH }\end{array}$ \\
\hline Testosterone & $\begin{array}{l}\text { Acutely vasodilates; long-term studies not available in } \\
\text { pulmonary hypertension models }\end{array}$ & No data \\
\hline DHEA & May be favorable in mouse models of pulmonary hypertension & $\begin{array}{l}\text { Higher levels associated with lower RV mass in healthy } \\
\text { individuals; no data on DHEA in PAH }\end{array}$ \\
\hline
\end{tabular}

DHEA: Dehydroepiandrosterone; PAH: Pulmonary arterial hypertension; RV: Right ventricle.

Modified from [1]. 